\title{
Euskokantauriar arroko eboluzio geologikoa I: estentsioaren eraginpean
}

\author{
Arturo Apraiz* \\ Geodinamika saila. Zientzia eta Teknologia Fakultatea (UPV/EHU) \\ Arantza Aranburu, Miren Mendia \\ Mineralogia eta Petrologia saila. Zientzia eta Teknologia Fakultatea (UPV/EHU) \\ Arantxa Bodego \\ Meatze eta Metalurgia Ingenieritza eta Materialen Zientzia saila \\ Meatzen eta Herri Lanen I.T.U.E. (UPV/EHU) \\ *arturo.apraiz@ehu.eus
}

DOI: $10.1387 /$ ekaia.14370

Jasoa: 2015-04-27

Onartua: 2015-10-07

Laburpena: Euskokantauriar arroaren eboluzioak oso iraupen luzea du. Goi Permiarrean hasi zen, eta azken prozesuak Miozenoan gertatu ziren. 250 Ma inguru horietan zehar, aldaketa nabarmenak izan dira bai erregimen tektoniko nagusian (luzapena, konpresioa), bai plaken arteko muga aktiboarekiko distantzian (rifta, ertz pasiboa, ertz aktiboa), eta bai azpiko lurrazal kontinentalaren izaeran (mehetua edo hipermehetua). Euskokantauriar arroak, oro har, eboluzio-prozesu konplexua du, baldintza tektoniko nagusiei egokituz pixkanaka aldatu zena.

Hitz-gakoak: Euskokantauriar arroa, estentsioa, arro sedimentarioa, eboluzio tektonosedimentarioa

Abstract: The Basque Cantabrian basin has a very long evolutionary history. It started in the early Permian, and the latest evolutionary steps took place in the Miocene. During those $250 \mathrm{My}$ significant changes happened in the dominant tectonic regime (extension, compression), in the distance to the plates limit (rift, passive margin, active margin), and the nature of the underlying continental crust (extended or hyperextended). The Basque Cantabrian basin has a complex evolution, controlled by the dominant tectonic conditions.

Keywords: Basque Cantabrian basin, extension, sedimentary basin, tectonosedimentary evolution. 


\section{SARRERA}

Geografiaren ikuspegitik, gaur egun alderantzikatuta dagoen Euskokantauriar arroan sartzen dira Nafarroako iparraldea, EAE Erkidegoa, Burgos eta Palentzia probintzietako iparraldea eta Kantabriaren zati handi bat. Geologiaren ikuspegitik, berriz, Pirinio mendikateko toles eta zamalkaduren gerrikoari dagokio Euskokantauriar arroa; zona horren mendebaldeko sektoreari Kantauriar mendikatea deritzo, eta bi sektoretan banatzen da: Asturiar mendigunea eta Euskokantauriar arroa (1. irudia). Euskokantauriar arroaren ekialdeko muga Iruñeko failan kokatzen da; mendebaldekoa, berriz, Asturiar mendiguneko materialekiko ukipenean dago. Iparraldeko eta hegoaldeko mugak, berriz, zamalkadura-fronte banari dagozkio, non Euskokantauriar arroko materialak Landetako mendiguneari eta Dueroren eta Ebroren Zenozoikoko arro deformatugabeei gainjartzen baitzaizkie, hurrenez hurren (1A eta 1B irudiak).

Euskokantauriar arroaren ezaugarri geologiko deigarriena Mesozoikoko materialen lodiera handia da, segur aski; bereziki Kretazeokoarena. Egin diren kalkuluen arabera, segida horren lodiera maximoa $12 \mathrm{~km}$ [1] eta $18 \mathrm{~km}$ [2] bitartean dago. Permikoko materialen presentzia arroaren ekialdeko eta mendebaldeko muturretara mugatuta dago. Zenozoikoko materialak, aldiz, arruntak dira; nagusiki bi sinklinorioren nukleoan eta Gipuzkoako monoklinalean azaleratzen dira (1.1B irudia).
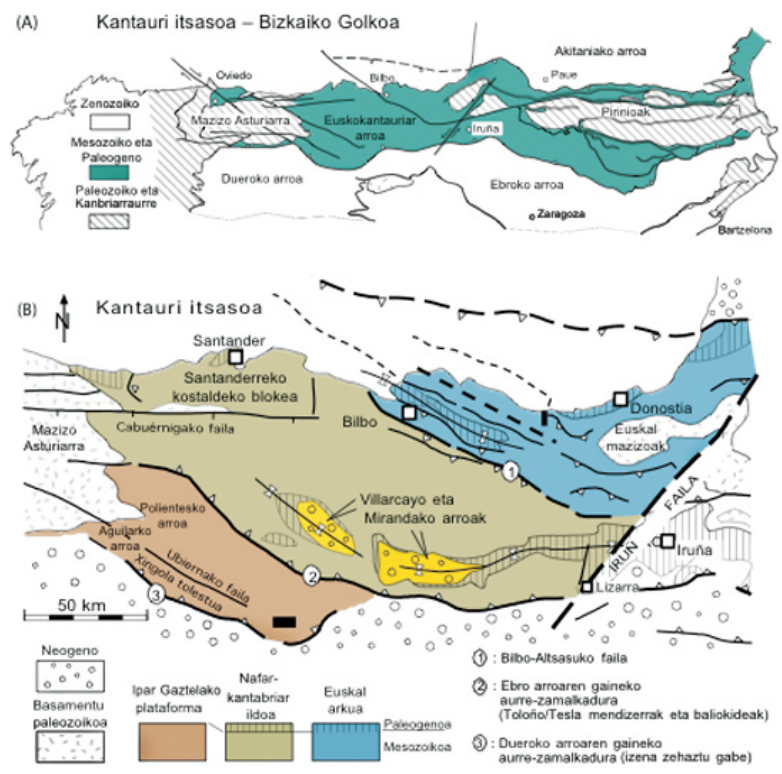

1. irudia. (A) Euskokantauriar arroaren kokalekua. (B) Euskokantauriar arroaren banaketa ([2]-tik moldatua). 
Euskokantauriar arroaren eboluzio geologikoaren funtsezko ezaugarriak adierazteko, bi egoera tektoniko bereizi dira; alde batetik, lan honetan lantzen den estentsio-urratsa eta, bestetik, honen jarraipena den bigarren lan batean lantzen den konpresio-urratsa [3]. Estentsio egoerarako eboluzio-etapa hauek definitu dira: Triasikoko riftaren etapa, rift-arteko etapa, Bizkaiko golkoko riftaren etapa, kontinente-ertz pasiboaren etapa. Konpresio egoerarako, aldiz, N-ranzko eta S-ranzko bergentziako fase tektonikoak bereizten dira.

\section{ESTENTSIOA NAGUSI DEN BITARTEAN}

\subsection{Arroaren jatorria: Triasikoko riftaren etapa}

Estentsioaren lehen etapa goi Permiarrean hasi eta Triasikoan garatu zen, nagusiki. Etapa horretan, Buntsandstein, Muschelkalk eta Keuper fazieseko metakinak eratu ziren, Europako erdialde eta mendebalde gehienean bezala.

Etapako subsidentzia distentsio-hausturaz gertatu zen nagusiki. Horren bitartez subsidentzia diferentzial handiko sakonune tektonikoak garatu ziren eta, beraz, lodiera estratigrafikoan aldaketa ikusgarriak izan ziren, bereziki Buntsandsteineko faziesetan (2. irudia). Buntsandsteineko fazies ibaitarrak (konglomeratuak, hareharriak eta lutitak) diskordantzia angeluarrean kokatzen dira, arroaren zokaloaren parte diren Karboniferoko edo behe Permiarreko materialen gainean. Muschelkalk faziesa tartean dagoen unitatea da, sakonera txikiko karbonatozko arrapalako materialez osatua. Gaineko unitatea, aldiz, arroka igneo ofitikoen intrusioak dituzten lutita- eta ebaporita-metakinez (Keuper faziesa) dago eratua.

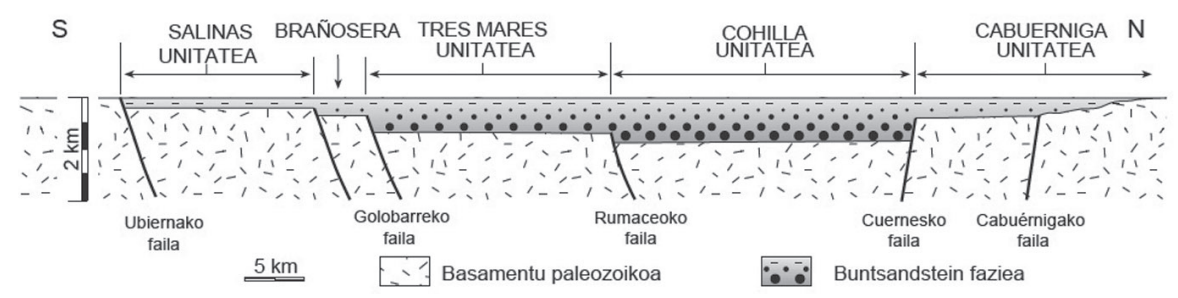

2. irudia. Buntsandsteineko sakonune tektonikoaren zehar-ebaki eskematikoa (goi Permiarra-Behe/ErdiTriasikoa), Euskokantauriar arroko mendebaldean ([2]-tik moldatua).

Buntsandsteineko materialen metaketa baldintza klimatiko nahiko lehorretan eta erdilehorretan gertatu zen; meteorizazio kimikoa urria izan zen, eta, hala, aro horretako materialek kolore gorrixka tipikoa hartu zuten. 
Muschelkalkeko itsasoa sakonera txikikoa zen, eta haren ipar-mendebaldeko muturra, Iberiar plakakoa, Euskokantauriar arroari zegokion, nahiz ez zuen osorik estaltzen. Geroago, Tetis itsasoaren ekialderanzko erregresioaren ondoren, Keuper fazieseko materialak eratu ziren sebkha motako kostako lautada zabaletan.

Fase honetako azaleramenduak aurki daitezke mendebaldeko (Nansa ibaiaren zehar-ebakian -Kantabria-; Alto Campóon, _Palentzia eta Kantabrian -; Peña Labrako mendilerroan-Kantabriaren eta Palentziaren arteko mugan-) eta ekialdeko muturretan (Oiartzun eta Andoain inguruan - Gipuzkoa-; eta Aurtitzen, Mendaur mendian eta Otsondoko mendatean -Nafarroa-).

\subsection{Triasikoko rifta bertan behera gelditzen da: rift-arteko etapa}

Rift-arteko etapa Triasikoaren bukaeran hasi zen, eta Behe eta Erdi Jurasikoan jarraitu zuen. Hala, haren garapenak duela 210 Ma-tik duela 160 Ma-ra bitarte iraun zuen. Adin tarte horretan, arroa sakonera txikiko itsaso zabal baten parte zen, iparraldean zegoen itsas domeinu Borealaren eta hego-ekialdean zegoen Tetis itsaso oso zabal eta epelaren artean kokatua. Hego-mendebaldetik eta ipar-mendebaldetik urgainetik azaleratutako eremuek mugatuta zegoen; hurrenez hurren, Iberiar mendigunea eta Armorikar mendigunea. Ammoniteen asoziazioek adierazten dute Euskokantauriar arroko itsasoa itsaso Borealarekin eta Tetis itsasoarekin bat eginda zegoela.

Baldintza hauetan sortzen den karbonatozko unitatearen faziesa eta lodiera oso gutxi aldatzen dira, albo-hedapen horizontal handia denez gero. Ezaugarri horiek iradokitzen dute aldaketa bat egon zela erregimen tektoniko sinsedimentario nagusian: aurreko etapako subsidentzia diferentzial handitik alboka aldaketa progresiboak dituen subsidentzia apalago batera pasatzen da. Hondorapen apala flexio-subsidentziaren eta subsidentzia termikoaren ondorioa izan daiteke.

Beraz, etaparen erregistro sedimentarioa itsas inguruneko materialei dagokie; horregatik, arroaren eskalan, «Jurasiko itsastar» ere baderitzo. Aldi horretan, itsas transgresio eta erregresioaren zenbait ziklo gertatu ziren, kosta-lerroaren desplazamendua, itsasoaren sakoneraren aldaketak eta askotariko materialen metaketak (bereziki karbonatozkoak eta tupatsuak) eragin zituztenak (3. irudia).

Horrenbestez, Jurasikoko sedimentazio itsastarra nahiko testuinguru tektoniko lasaian gertatu zen, nahiz eta orduko unitate estratigrafikoen lodiera-aldaketek adierazten duten izan zirela eskala lokaleko subsidentzia desberdintasunak, baina beti izaera progresibokoak (4. irudia). 


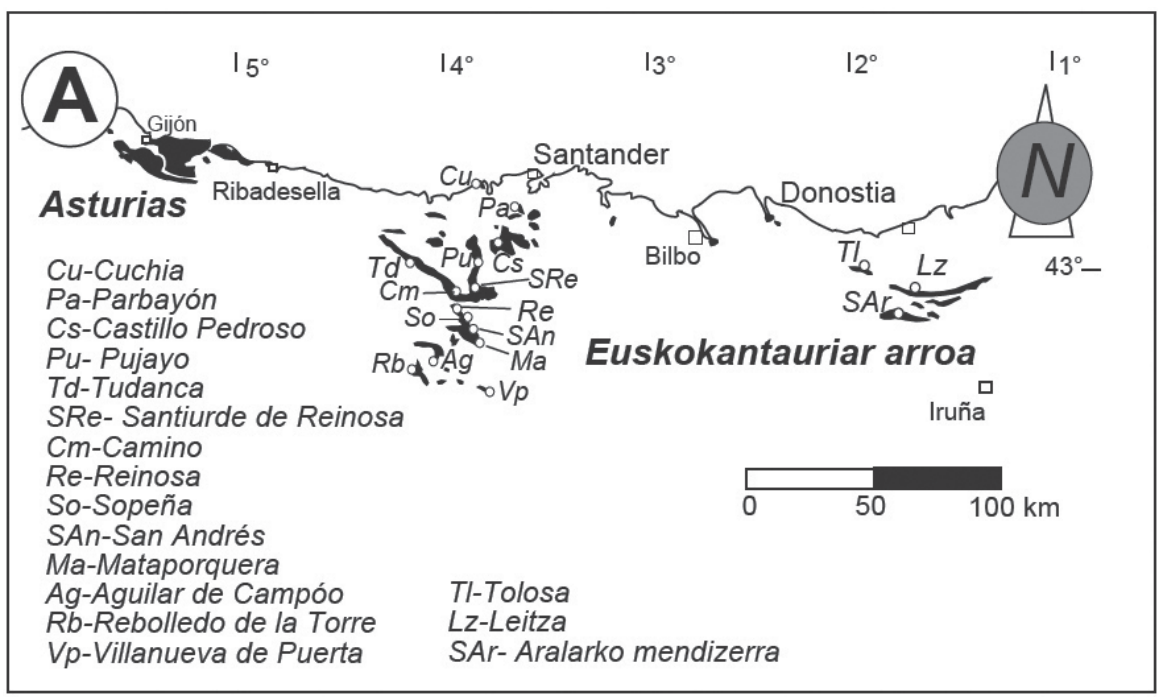

3. irudia. Euskokantauriar arroko eta Asturiaseko Jurasiko itsastarreko azaleramenduak (Noriar-Rhaetiarra barne) ([2]-tik moldatua).

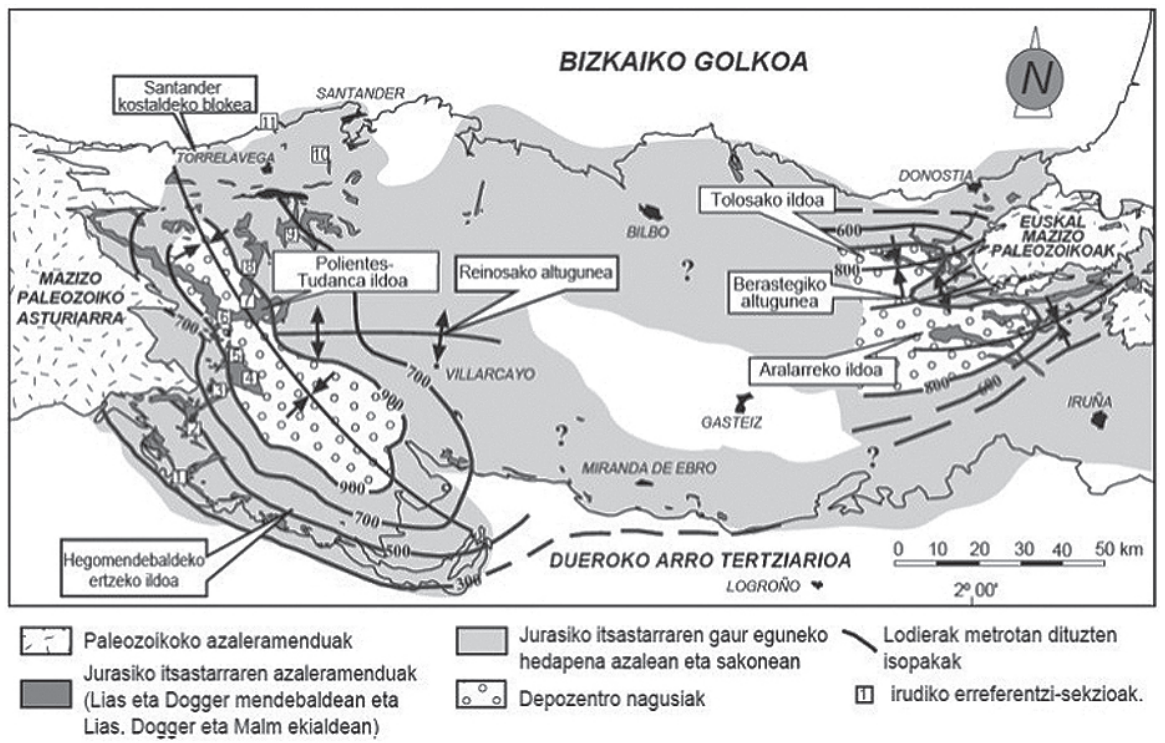

4. irudia. Euskokantauriar arroko Jurasiko itsastarreko isopaken mapa, ildoen eta altuguneen kokapena eta orientazioa erakusten dituena (ildoak, subsidentzia eta metatze sedimentario maximoa duten inguruak; altuguneak, inguru erlatiboki goratuak eta metatze gutxiago dutenak). ([2]-tik moldatua). 
Etapa horretako azaleramendu nagusiak arroaren mendebaldean daude (Kantabrian eta Palentziako eta Burgosko iparraldean). Jurasiko itsastarra arroko beste toki batzuetan ere azaleratzen da, baina xumeago: arroaren ekialdeko muturrean (Bortzirietako mendiguneko ertzetan, bai Gipuzkoan eta bai Nafarroan; eta Tolosaren eta Azkoitiaren artean); erdigunean (Aralarko mendilerroa); Bizkaiko kostaldean (Urdaibaiko itsasadarra eta $\mathrm{Au}-$ lesti); eta arroaren hegoaldeko ertzean (Montoria, Toloñoko Mendilerroan, eta Nograro; biak Araban) (3. irudia).

Euskokantauriar arroko Jurasiko itsastarrean bi unitate estratigrafiko informal handi bereizi dira, haien ezaugarri litologikoak, ingurunea eta adina kontuan hartuta [4]:

a) Sakonera txikiko karbonatozko arrapala, Triasikoaren bukaera eta Behe Jurasikoaren erdi artekoa, $100 \mathrm{~km}$ baino gehiagoko zabalera izatera iritsi zen.

b) Arrapala hemipelagikoa, Behe Jurasikoaren beste erdia eta Erdi Jurasikoa. Eremu horretan, jatorria itsasoan duten lohi karbonatatu biogenikoak eta jatorri kontinentala duten material terrigeno buztintsuak txandakatuta edo nahastuta ageri dira, nagusiki. Sedimentu horiek serie erritmikoak eratu ohi dituzte, kareharrien eta tupa grisen txandakatzez eratuak, eta fosil nektonikoak (hala nola ammoniteak eta belemniteak) eta fosil bentonikoak (hala nola brakiopodoak) barneratzen dituzte.

Jurasikoko bi unitateen arteko muga transgresio-azalera batek markatzen du, itsas mailaren goratze erlatibo bizkor eta bortitz batek eragindakoa. Fenomeno hori eskualde eskalako subsidentzia tektonikoak eragin zuen, baina oso iraupen laburrekoa da (goi Sinemuriarraren hasiera, $195 \mathrm{Ma}$ inguruan). Jurasiko itsastarreko bi unitate nagusien arteko kontaktua islatua gelditzen da beti faziesen bat-bateko aldaketarekin: sakonera txikiko fazies karedunak edo detritikoak izatetik ammoniteak dituzten kareharri edo tupa hemipelagikoak izatera pasatzen dira.

Etaparen bukaera Erdi Jurasikotik aurrera gertatzen da. Arroak erregresio bat jasaten du, azaleratu egiten da eta airepeko higadura nabarmenaren eraginpean gelditu. Erregresio-prozesu horrek higadura orokor bat eragiten du, rift-arteko etaparen amaiera eta Euskokantauriar arroaren eboluzioko hurrengo etaparen hasiera adierazten duena.

\subsection{Bigarren ahalegina; Iberiar eta Europar plakak bereizi egiten dira: Bizkaiko golkoko riftaren etapa}

Etapa honetan (Goi Jurasikoa eta Behe Kretazeoa), Atlantikoaren irekierak eta haren ondorioz gertatu zen Europar eta Afrikar plaken eta Ipa- 
rramerikar plakaren bereizketak kontrolatu zuten Euskokantauriar arroaren eboluzioa. Egoera horretan, Iberiar plaka erloju-orratzen norabidearen aurka biratu zen Eurasiarekiko nahiko era independentean [5], eta, ondorioz, Iberiar eta Europar plakak elkarrengandik bereizten hasi ziren, eta Bizkaiko golkoa irekitzen hasi, kontinente-lurrazalaren apurketa-prozesu baten bidez (hipermehetutako lurrazala) [6]. Biraketa-prozesua izan zen bitartean, arroak estentsio-esfortzu nabarmenak jasan zituen.

Bizkaiko golkoko riftaren etapa arroaren gorakada orokor batekin hasi zen, astenosferaren goranzko bultzadak eraginda. Estreinako gorakadaren eta higadura fasearen ostean, estentsio-aldi luze bat izan zen Euskokantauriar arroan. Horretan, faila listrikoak eta okerdura handiko faila normalak dira egitura nagusiak. Faila horiek arroa sakonune eta altugune topografikoetan (grabenak eta horstak) zein faila listrikoetan garatutako bloke kulunkatuetan banatzen dute (5. eta 6. irudiak).
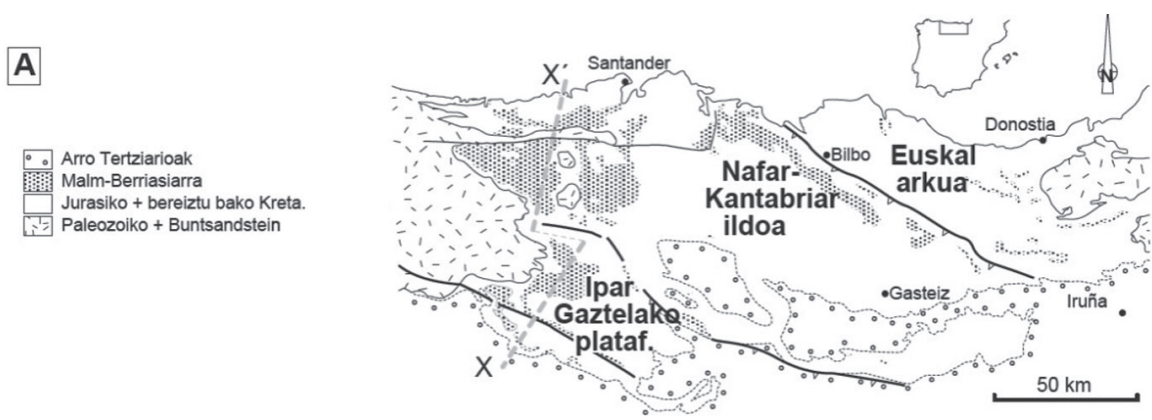

5. irudia. Bizkaiko golkoko riftaren etapako beheko unitateen azaleramenduak (Tithoniar-Barremiarra), haiek metatu zirenean aktibo zeuden faila nagusien trazadura (hegoaldetik iparraldera: Ubiernako faila, Rumaceoko faila eta Cabuérnigako faila) eta 6 irudiko zehar-ebakiaren kokapena ([2]-tik moldatua).

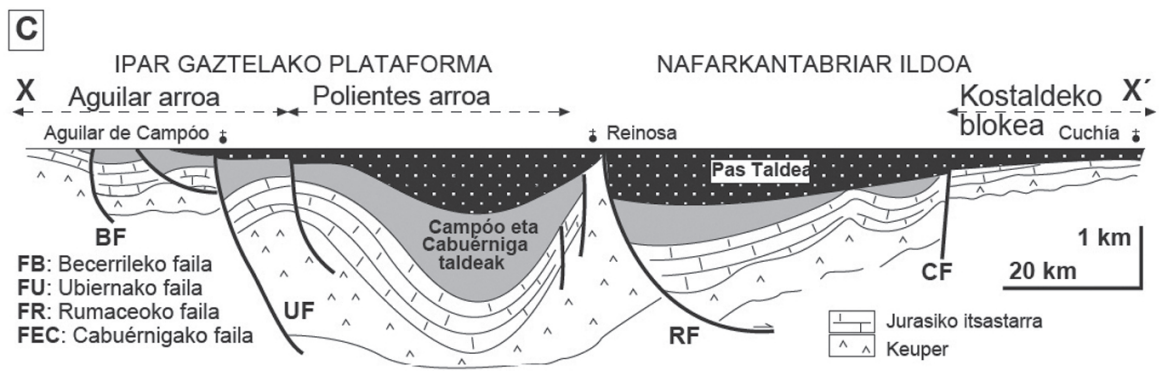

6. irudia. Zehar-ebaki sinplifikatua. Bizkaiko golkoko riftaren etapa goiztiarrean arroko mendebaldean aktibo zeuden eta metakin kontinental eta trantsiziozkoen (Campóo, Cabuérnigaeta Pas Taldeak) metaketa (goi Tithoniar-Barremiarra) kontrolatu zuten failak ageri dira ([2]-tik moldatua). 
Bizkaiko golkoko riftaren etaparen amaiera ez zen bat-batekoa izan, baizik eta nahiko trantsiziokoa edo progresiboa. Bizkaiko golkoko lehen ozeano-lurrazala Aptiarrean eratu zen Bizkaiko protogolkoko mendebaldean, baina Albiar eta behe Cenomaniarrera arte izan ziren rifting-gertaerak.

Bizkaiko golkoko riftaren etaparen eboluzioa honela bana daiteke: a) rift goiztiarraren etapa (goi Tithoniarra-Barremiarra); b) tarteko riftaren etapa (Aptiarra-behe Albiarra) eta; c) rift berantiarraren (behe eta erdi Albiarra) eta rift-osteko etaparako trantsizio-etapa (goi Albiarra-behe Cenomaniarra).

\subsubsection{Rift goiztiarraren etapa: failak berraktibatzen dira}

Arroak, mendebaldean eta hego-mendebaldean, bere bilakaerarekin jarraitu zuen E-W eta NW-SE norabideko zokalo-faila nagusien berraktibazioaren bidez eta haiekin erlazionatutako faila sinsedimentario listrikoen sorreraren bidez (7. irudia). Faila horiek sakonune topografiko edo grabenak eratu zituzten [7]; hasieran, bakartuak zeuden eta txikiak ziren, baina pixkanaka hedatu egin ziren, eta ertzak unitate sedimentario gazteenekin estali ziren, hegoalderantz eta iparralderantz.
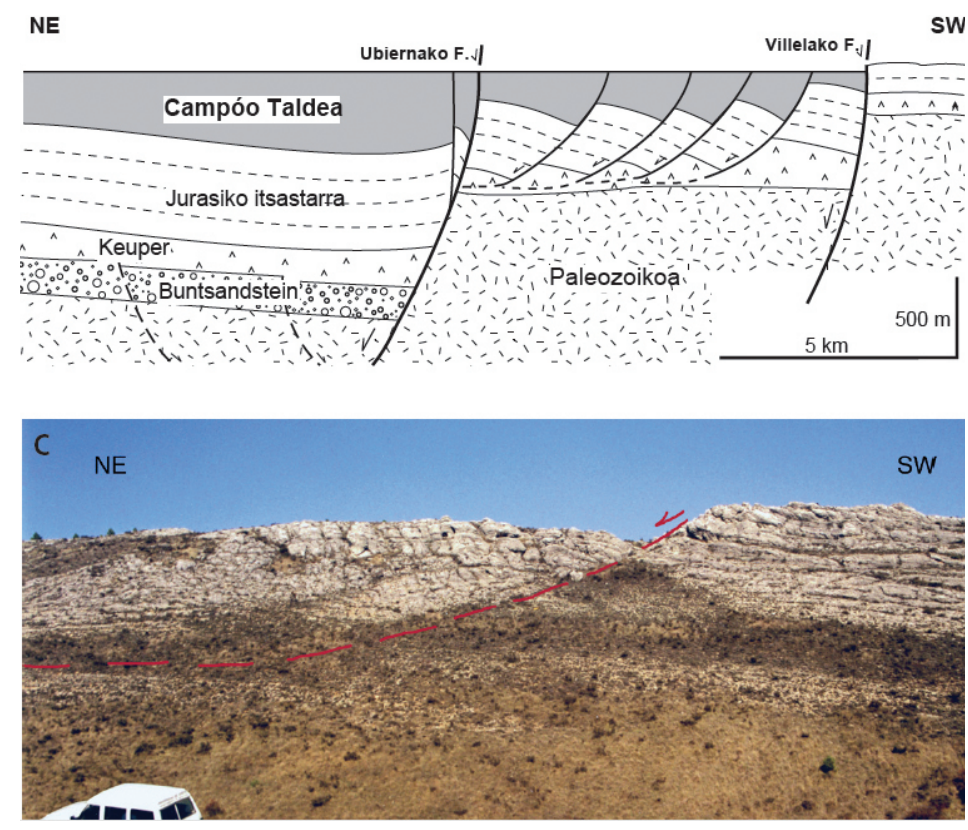

7. irudia. (B) Aguilar de Campóo inguruko zehar-ebaki sinplifikatua; arro horretako Campóo Taldeko metaketa ere ageri da (alubial-zingiratarra). C) Rifteko faila listriko baten adibidea, Becerril del Carpio ingurukoa (Palentzia), Doggerreko materialei eragiten diena eta blokeak hego-mendebalderantz baskularazten dituena ([2]-tik moldatua). 
Arroko mendebaldean eta erdialdean (Kantabrian, Palentziako eta Burgosko iparraldean eta Bizkaiko mendebaldean), metakin kontinentalak (ibai-alubialak eta zingiratarrak) eta trantsiziokoak pilatu ziren nagusiki etapa honetan. Arroko ekialdean (Bizkaiko ipar-ekialdean, Gipuzkoan eta Nafarroako iparraldean), etapa honetako materialak diskordantzian daude karstifikazio-azalera baten gainean.

\subsubsection{Tarteko riftaren etapa: fazies Urgondarra, arrezifeak baino zerbait gehiago}

Etapa honetan (Aptiarra-behe Albiarra), bereizgarri dira tektonismoaren moteltzea eta subsidentzia progresibo orokor bat, zeinak, itsas mailaren gorakada globalarekin batera, arro mailako transgresioa eragin zuen [8]. Etapa honetan eratu ziren fazies Urgondar bereizgarriak. Fazies horietan nagusi dira sakonera txikiko itsas inguruneetako karbonato biogenikoak [9]. Euskokantauriar arroaren eta Tetiseko ur epelagoen arteko loturak arrezife-fazies zabalen garapena sustatu zuen, koral eta errudista ugariekin.

Etapa honen hasieran (behe Aptiarra), ibai-inguruneak garatu ziren arroko hegoaldean eta mendebaldean. Iparralderantz eta ekialdeko ertzerantz, aldiz, sakonera txikiko plataforma lohitsu eta trantsizioko ingurune terrigeno bilakatzen dira, eta bertan garatu ziren lehen ostreido eta errudista multzo bakartuak. Baldintza horiek bizkor aldatu ziren, ordea, behe Aptiarreko transgresioaren ondorioz; sakonera txikiko karbonatozko sedimentazioa (Urgondarreko faziesak) arroko eremu zabaletara bizkor hedatzea eragin zuen transgresio horrek. Aptiarrean, sakonera txikiko eta malda leuneko arrapala-sistemak garatu ziren, alboetarantz eremu sakonagoetara igarotzen zirenak, non tupak eta kareharri tupatsuak metatzen baitziren.

Goi Aptiarrean, arroko eremu erlatiboki sakonetan (Bilboko ildoa, Euskal ildo zabalaren barruan) tupak metatu ziren nagusiki, nahiz eta izaera turbiditikoko beste sedimentu siliziklastiko batzuk ere agertu. Hego-mendebaldeko (Iberiar) eta ipar-ekialdeko (Landetako eta Bortzirietako mendigunea) ertzetan, berriz, sakonera txikiko itsas sedimentazioa zen nagusi, hala karbontozko (altugune erlatiboetan) nola detritikoa (gune hondoratuenetan). Hegoaldean, aldiz, Iberiar ertz zabaleko kanpoaldean zeuden inguruetan, metakin detritikozko ibai-lautada zabala garatu zen.

Urgondar kareharriak luze eta zabal azaleratzen dira arroan, mendi eta mendilerro garrantzitsuei dagozkien altugune topografikoak eratuz. Nabarmentzekoak dira, Kantabrian, La Sía eta Alisas arteko azaleramenduak, bai eta Oriñón, La Cavada, Reocín eta Suanceskoak ere; Bizkaian, aipatzekoak dira Jorrios eta Raneroko mendiguneak; Bilboko antiklinorioaren zonan, Sopuerta-Galdames meatze-ingurunearen eta Orozkoren artekoak; Urdaibai ingurunea (Ereño-Markina eta Forua-Mendaka); Gorbeia (Itxina); Aramotz mendigunea (Durangaldea) (8. irudia); Gipuzkoan, 
Andutz, Hernio, Uzturre eta Pagoeta mendiguneetan azaleratzen direnak; Bortzirietako mendigunearen orlakoak (Asteasu-Hernani eta Txoritokieta); Mutiloako domoan; eta Aralarren (8. irudia) eta Baztan aldean Nafarroan ere azaleratzen dena.
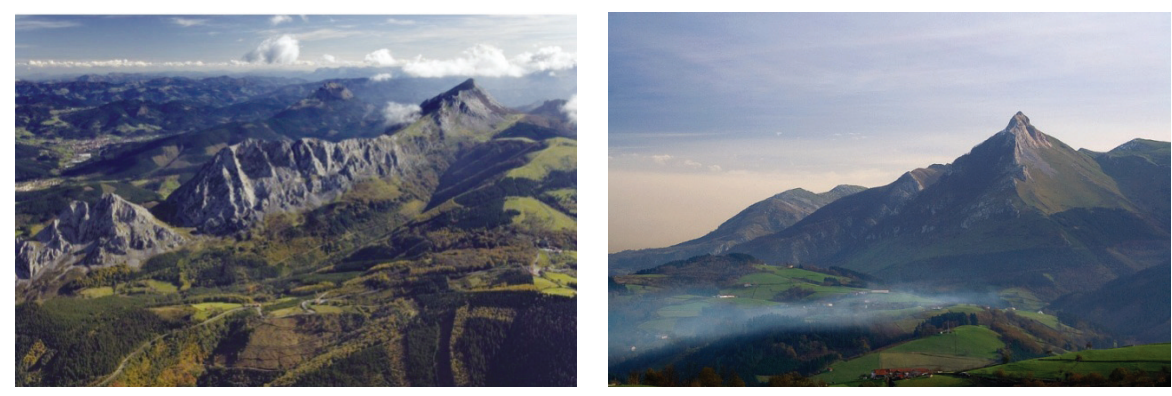

8. irudia. Urgondar kareharrien azaleramenduak, Aramotzko mendizerran (Bizkaia) etaTxindoki mendian (Gipuzkoa) Aralarren.

\subsubsection{Rift berantiarraren etapa eta rift-ondoko etaparako trantsizioa: arroa hondoratu egiten da}

Etapa honek behe eta erdi Albiarra (rift berantiarra) eta goi Albiarra -behe Cenomaniarra (rift-ondoko etaparako trantsizio-aldia) hartzen ditu. Etapa hau, oro har, flysch-etapa izenaz da ezaguna ere, orduan pilatu baitzen Flysch Beltza. Flysch horretako materialen bereizgarria da oso kolore iluneko lutitak eta hareharri eta/edo konglomeratuak txandakatuak izatea. Material horiek arro sakon samarreko sedimentazio itsastarreko lehen agerpena dira, eta, funtsean, uhertasun-korronteek eta beste grabitazio-fluxu batzuek eratu zituzten.

Etapa honen hasiera eta garapena (behe-erdi Albiarra) rifting-prozesua berraktibatu zuten pultsu tektonikoek baldintzatu zuten; pultsu horiek, hala, subsidentzia diferentzial maximo bat eragin zuten failek mugatutako bloke hondoratuetan eta, era berean, flysch motako faziesak metatu zireneko lehen ildoen garapena eragin zuten.

Albiarrean, Euskokantauriar arroko paleogeografian, Iberiar ertza arroaren hegoaldean zegoen kokatuta eta arroaren iparraldean Europar ertza; bigarren hori Landetako mendigunearen eta Bortzirietako mendigunearen hegoaldeko ertza zen (9. eta 10. irudiak). Bi ertzen artean, subsidentzia handiko itsas ildo sakon samarra zegoen, WNW-ENE orientazioa zuena. Bertan metatu zen turbidita-segida lodi bat (Flysch Beltza). Ildoa bat dator, gutxi gorabehera, Iberiar plakaren eta Europar plakaren arteko mugaren mendebaldeko trazadurarekin (10. irudia). Arroaren ertzetan oso hedakorrak izan ziren etapa honetako unitate estratigrafikoak. 


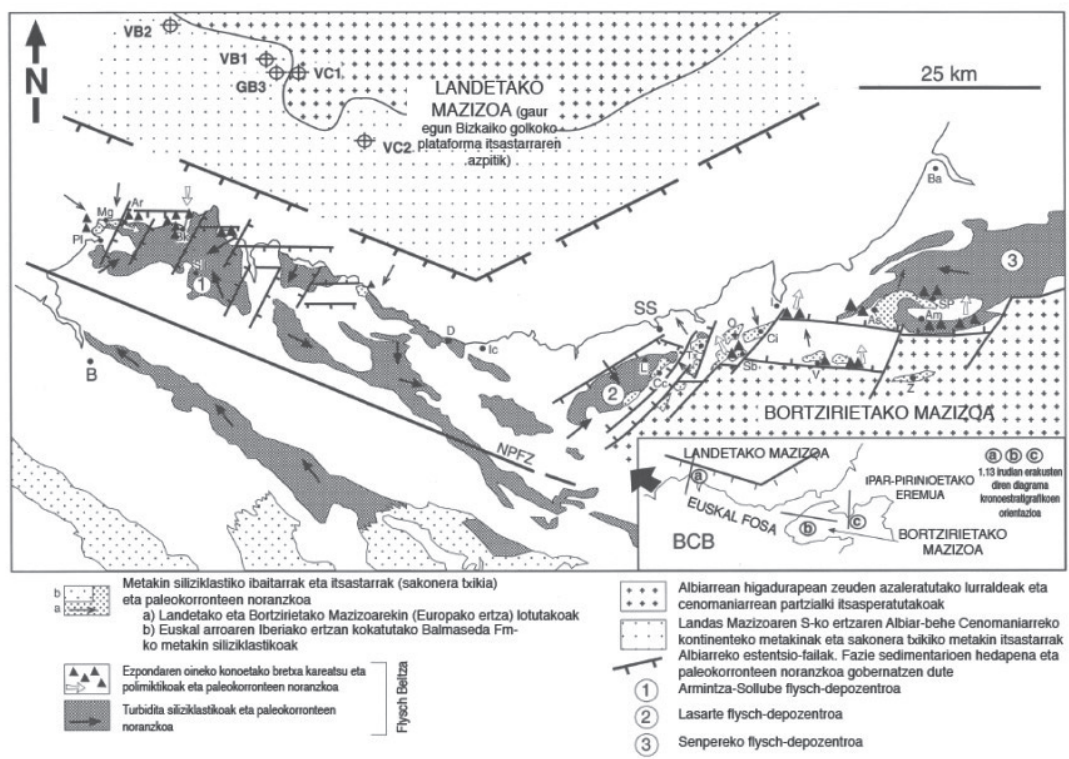

9. irudia. Euskokantauriar arroko eta Ipar Pirinioko mendebaldeko muturreko mapa paleotektonikoa. Bizkaiko golkoko riftaren etapa berantiarrean eta rift-ondoko etaparako trantsizioan (Albiar-behe Cenomaniarra) ([2]-tik moldatua).

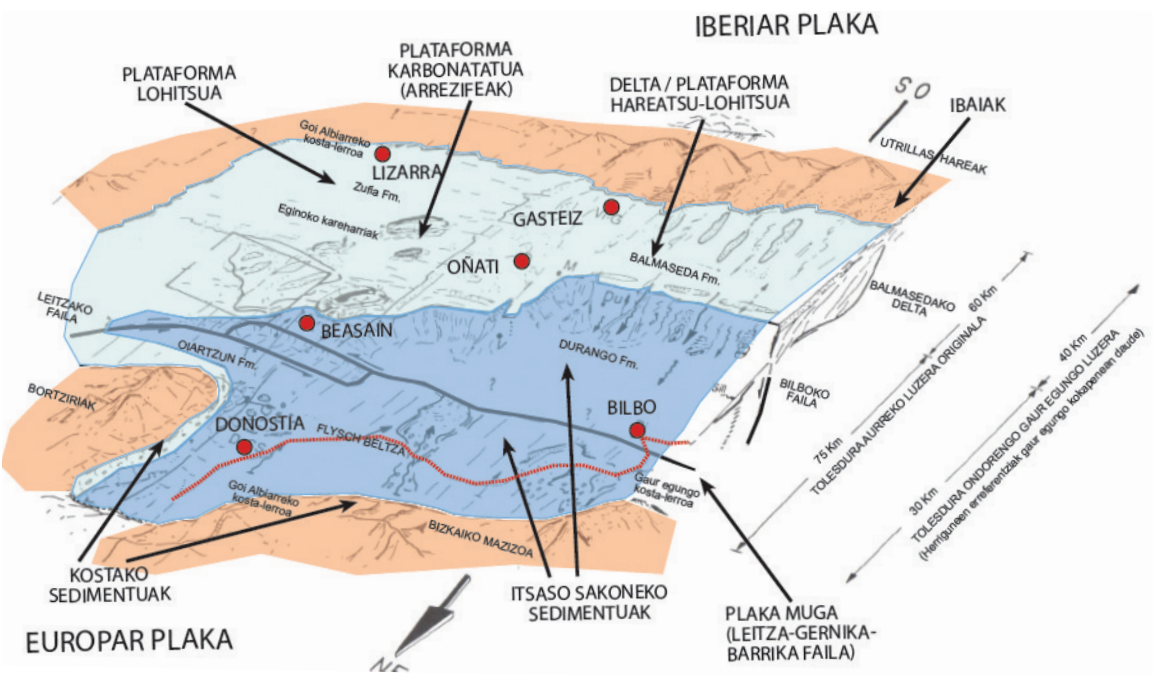

10. irudia. Albiarrean kostaldeko sedimentuen, karbonatozko plataformen eta sakoneko sedimentuen kokapena erakusten duen eskema paleogeografikoa ([2]-tikmoldatua). 
Etapa honetan sortu zen, era berean, Euskal Arku deritzon antolaera tektonoestratigrafikoa. Euskal Arku deritzo arroko egitura eta materialek duten geometriari; bat-bateko aldaketa bortitz bat du haien orientazioak: NW-SE erdialdean eta mendebaldean, eta SW-NE, berriz, ekialdean (9. irudia).

Behe eta erdi Albiarrean, arroaren hegoaldeko ertzean, aurreko etapan garatu ziren karbonatozko plataforma Urgondar zabalak puskatu, kolapsatu eta hondoratu ziren $[8,10,11]$. Faila horietako bloke goratuetan jarraipena izan zuen sakonera txikiko itsas inguruneetako karbonatozko unitateen garapenak. Bloke garai horietako batzuen ertzak tamaina eta malda handiko ezpondei zegozkien, hala nola, Itxinako (Gorbeia) karbonatozko plataformaren iparmendebaldeko ezponda [12].

Erdi Albiarrean, failetako bloke goratuetan garatutako karbonatozko plataforma gehienak urgaineratu egin ziren eta karstifikazio-prozesu sakona jasan zuten $[13,14]$; ondoren, plataforma horien ertzetako hondoratze orokor bat gertatu zen. Urgaineratutako plataformen tartean zeuden sakonune eta paleoarroilak eta arroko eremu sakonenak (Bilboko ildoa) tupa, lutita, lohi-harri eta turbidita hareatsuen pilaketa lodi batez bete ziren.

Etapa honen amaieran (goi Albiar-behe Cenomaniar) Iberiako ertzean ibai-sedimentuak (hareak eta legar gutxi batzuk) metatzen dira (Utrillas Formazioa). Fazies horiek, iparralderantz, ekaitzek gobernatutako plataforma siliziklastiko (sakonera txikiko itsas sistema terrigeno zabal eta lodia, Balmaseda Formazioa) bilakatzen dira (10. irudia). Arroaren erdialdean, aldiz, Euskal Ildoa kokatzen zen garai horretan, hegoaldean Iberiar ertzak eta iparraldean Landetako mendigune urgaineratuak mugatua [15], tartean Bortzirietako mendigune urgaineratua zegoela.

\subsection{Kontinente-ertz pasiboaren etapa: itsasoa ozeano bihurtu nahi}

Ertz pasiboaren etaparen hasiera erdi Cenomaniarrean koka daiteke. Orduan, subsidentzia termikoa eta haren ondoriozko sedimentazioa izan ziren arroko prozesu nagusiak. Aptiarrean aurrera darrai Bizkaiko Golkoaren mendebaldean hasi zen ozeano-lurrazalaren eraketak eta, ondorioz, kontinente-ertzak urrundu egiten dira ekarpen magmatikoa eta termikoa dagoen ingurutik. Horrela, kontinente-litosferaren dentsitatea handitu egiten da hozte progresiboa gertatzen delako, eta arroaren hondorapen progresiboa gertatzen da. Kontinente-ertzaren eta ozeano-lurrazalaren genesiaren ondorioz, itsasoa zena ozeano bihurten hasten da. Baina Euskokantauriar arroan, nahiz eta itsaspeko bolkanismoa bizia izan [16], ozeano-lurrazalik ez zen sortu (azkeneko arrastoak Asturias-ko iparraldean gelditzen dira), eta ondorioz itsasoak ez zuen inoiz ozeano mailarik lortu.

Iberiar ertz zabalaren hegoaldean ingurune kontinentalak, itsasbazterrekoak eta sakonera txikiko plataformetakoak nagusitu ziren. Iparralderago, 
sistema hemipelagikoak; eta Euskokantauriar arroaren erdialdean, inguru sakonenean, sistema pelagikoak eta turbiditikoak garatu ziren. Gaur egun, erdigune horrek Bizkaiko ipar-ekialdea eta ia Gipuzkoa osoa hartzen ditu (11. irudia).

Etapa honetan, laburbilduz, hiru domeinu paleogeografiko handi bereizten dira. Hauek dira domeinu horiek, iparraldetik hegoaldera (11. irudia) [2]:

1. Landetako mendigunea eta Hegoakitaniar plataforma; arroaren iparraldeko ertz erlatibotzat har daiteke, eta hegoaldeko ertza edo Iberiar ertza baino askoz ere estuagoa da.

2. Flysch ildoa; arroaren erdigunea eta inguru sakonena, Euskal arkuarekin bat datorrena; han daude Iberiar eta Europar plaken arteko muga eta Euskal Herriko mendiguneak (Bortzirietakoarena, bereziki). Ildo honetan sortu ziren, bereziki, goi Albiar-behe Santoniar bitartean erregistratutako gertaera magmatiko gehienak. Bolkanismoak, beraz, itsaspean izan zuen eragina; izaera nagusiki efusiboa zuen, nahiz eta zenbaitetan leherkorra ere izan [13].

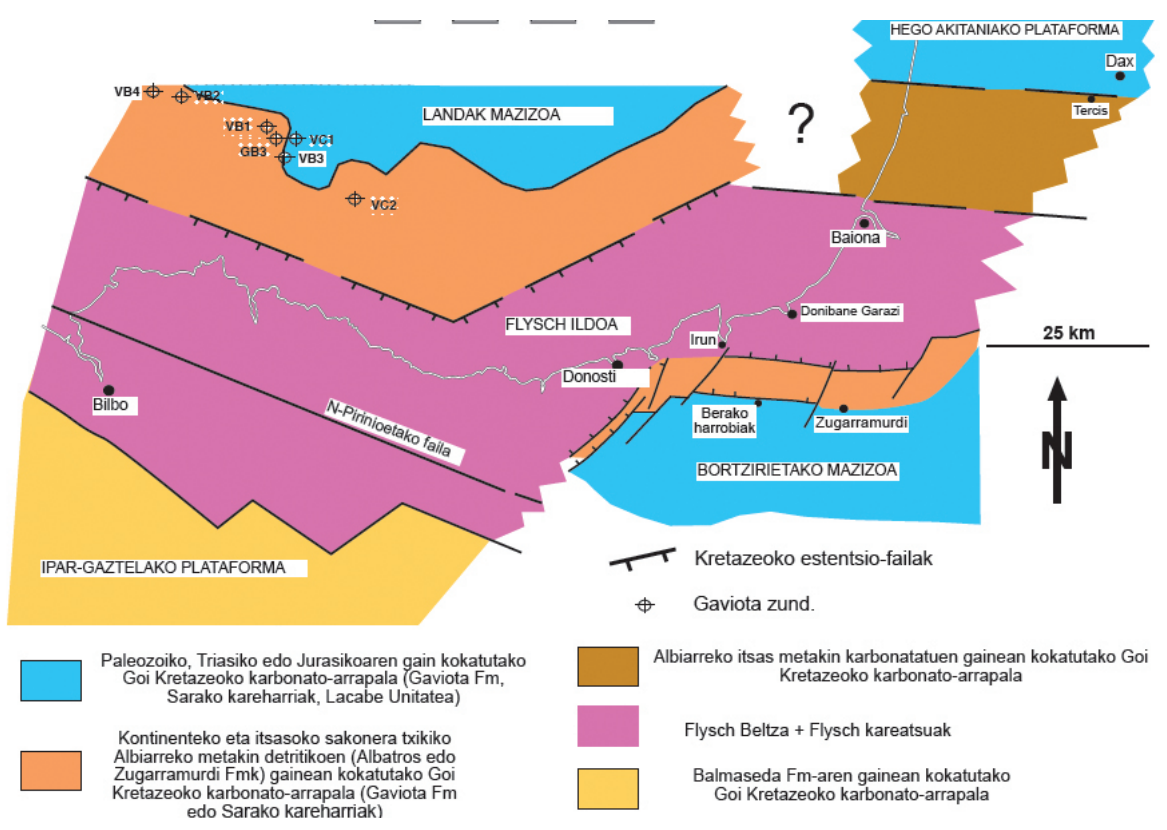

11. irudia. Euskokantauriar arroko eta haren mendebaldeko jarraipena den Ipar Pirinioko paleogeografiaren, domeinu tektono-estratigrafikoen eta fazies estratigrafikoen xehetasuna, kontinente-ertz pasiboaren etapakoa (neurri batean, Goi Kretazeokoa) ([2]-tik moldatua). 
3. Iberiar ertza, non bereizten baitziren Ipar Gaztelako plataforma eta Nafarkantabriar ildoa. Iberiar ertza, 100-250 km zabal, arroko unitate tektonoestratigrafiko zabalena zen garai hartan. Han, kanporago dagoen eta sakonera txikiagoa duen inguru bat bereizten da, Ipar Gaztelako plataforma, 50-200 km zabal den eta oso malda txikia duen arrapala batez osatua, zeina hego-ekialderantz luzatzen baitzen Iberiar arroan zehar. Ipar-ekialdean, berriz, malda eta subsidentzia handiagoko xingola bat zegoen, Nafarkantabriar ildoa, NWSE orientazioa zuena eta 40-50 km zabal zena, non Ipar Gaztelako plataforman baino segida lodiago eta sakonxeago bat metatu baitzen (17 irudia).

\section{ESKER ONAK}

Egileok eskertu nahi dugu Sergio Roblesek erakutsitako prestutasuna Euskokantauriar arroari buruz dakiena gurekin partekatzeko.

\section{BIBLIOGRAFIA}

[1] BRINKMANN, R. eta LÖGTERS, H. (1968). «Diapirs in Western Pyrenees and Foreland, Spain». Non: BRAUNSTEIN, J. eta O'BRIAN, G.D. (edk.). Diapirism and Diapirs. American Association of Petroleum Geologist Memories $8,275-292$.

[2] ROBLES, S. (2014). «Euskokantauriar arroko eboluzio geologikoa». Non: BODEGO, A., MENDIA, M., ARANBURU, A. eta APRAIZ, A. (edk). Euskokantauriar arroko geologia. Euskal Herriko Unibertsitateko Argitalpen Zerbitzua, Bilbo, 9-104.

[3] APRAIZ, A., ARANBURU, A., MENDIA, M. eta BODEGO, A. (prentsan). «Euskokantauriar arroko eboluzio geologikoa II: konpresioaren eraginpean». Ekaia.

[4] ROBLES, S., QUESADA, S., ROSALES, I., AURELL, M. eta GARCÍARAMOS J.C. (2004). «El Jurásico marino de la Cordillera Cantábrica». Non: VERA, J.A. (ed.). Geología de España. Sociedad Geológica de España-Instituto Geológico y Minero de España, Madrid, 279-285.

[5] OLIVET, J.L. (1996). «Cinématique de la plaque Ibérique». Bulletin des Centres de Recherche Exploration-Production Elf-Aquitaine, 20, 131-193.

[6] TUGEND, J., MANATSCHAL, G., KUSZNIR, N.J., MASINI, E., MOHN, G. eta THINON, I. (2014). «Formation and deformation of hyperextended Rift Systems: Insights from Rift domain zapping in the Bay of Biscay-Pyrenees». Tectonics, 33, 1239-1276. 
[7] PUJALTE, V., ROBLES, S., GARCÍA-RAMOS, J.C. eta HERNÁNDEZ, J.M. (2004). «El Malm-Barremiense no marinos de la Cordillera Cantábrica». Non: VERA, J.A. (ed.). Geología de España. Sociedad Geológica de España-Instituto Geológico y Minero de España, Madrid, 288-291.

[8] GARCÍA-MONDÉJAR, J., FERNÁNDEZ-MENDIOLA, P.A., AGIRREZABALA, L.M., ARANBURU, A., LÓPEZ-HORGUE, M.A., IRIARTE, E. eta MARTÍNEZ DE RITUERTO, S. (2004). «El Aptiense-Albiense de la Cuenca Vasco-Cantábrica». Non: VERA, J.A. (ed.). Geología de España. Sociedad Geológica de España-Instituto Geológico y Minero de España, Madrid, 291-296.

[9] GARCÍA-MONDÉJAR, J. (1990). «The Aptian-Albian carbonate episode of the Basque-Cantabrian basin (northern Spain): general characteristics, controls and evolution». Non: TUCKER, M.E., WILSON, J.L., CREVELLO, P.D., SARG, J.F. eta READ, J.F. (edk.). Carbonate Platforms: Facies, Sequences and Evolution. Backwell, IAS, Special Publications, 9, 257-290.

[10] ARANBURU, A., FERNÁNDEZ-MENDIOLA, P.A. eta GARCÍA-MONDÉJAR, J. (1992). «Contrasting styles of paleokarst infill in a blockfaulted carbonate ramp (Lower Albian, Trucios, N Spain) ». Geogaceta 11, 42-44.

[11] ROSALES, I., FERNÁNDEZ-MENDIOLA, P.A. eta GARCÍA-MONDÉJAR, J. (1994). «Carbonate depositional sequence development on active fault blocks». Sedimentology 41, 861-882.

[12] GÓMEZ-PÉREZ, I., FERNÁNDEZ-MENDIOLA, P. A. eta GARCÍAMONDÉJAR, J. (1999). «Depositional architecture of a rimmed carbonate platform (Albian, Gorbea, western Pyrenees)». Sedimentology 46, 337-356.

[13] ARANBURU, A. (1998).«El Aptiense-Albiense de Trucíos-Güeñes (oeste de Bizkaia)». Tesis Doctoral, Zientzia eta Teknologia Fakultatea, UPV/ EHU, 606 or.

[14] LÓPEZ-HORGUE, M.A., ARANBURU, A., FERNÁNDEZ-MENDIOLA, P.A. eta GARCÍA-MONDÉJAR, J. (2000). «Existencia de una discordancia angular con laguna de Albiense medio en el Complejo Urgoniano de Ranero (Ramales-Karrantza, región vasco-cantábrica)». Geogaceta 28, 89-92.

[15] GARCÍA-MONDÉJAR, J., FERNÁNDEZ-MENDIOLA, P.A., AGIRREZABALA, L.M., ARANBURU, A., LÓPEZ-HORGUE, M.A., IRIARTE, E. eta MARTÍNEZ DE RITUERTO, S. (2004). «Extensión del Aptiense-Albiense en la Cuenca Vasco-Cantábrica». Non: VERA, J.A. (ed.). Geología de España. Sociedad Geológica de España-Instituto Geológico y Minero de España, Madrid, 340-343.

[16] CARRACEDO, M., MENDIA, M., SARRIONANDIA, F. eta JUTEAU, T. (2014). «Kretazeoko itsaspeko bolkanismoa Euskokantauri ararroan». Non: BODEGO, A., MENDIA, M., ARANBURU, A. eta APRAIZ, A. (edk). Landa Geologia: 12 irteera Euskokantauri ararroan zehar. Euskal Herriko Unibertsitateko Argitalpen Zerbitzua, Bilbo, 33-50. 